in some phenomena than in others, and more evident at some moments than at others. The questions of the origin, the existence, and the value of species in such a system are ensily appreciated.

Thornhill, Feb. 23

\section{The Preponderance of West Winds}

IN NATURE of the 16 th inst. you appear to contest $\mathrm{Mr}$ Laughton's statement that west winds preponderate over east on the entire globe. I believe that Mr. Laughton is right as to the fact. We have no reason to think that the earth's atmosphere is acteil on from without by any force except the sun's heat ; if this is the case, the winds can have no effect whatever in either accelerating or retarding the earth's rotation ; and, conseqently, the east and west winds must exactly balance each other's effect, for if either were unbalanced it would have an effect, however small, on the earth's rotation. But " an east wind near the equator has more effect in retarding the rotation of the earth, than a west wind of equal extent and force at a higher latitude in accelerating it, just as a weight at the end of the long arm of a lever outweighs an equal weight at the end of the short arm. It is for this reason that the west winds, which are mostly in the higher latitudes, are of greater force, and probably cover a greater area than the east winds, which, under the name of trade winds, predlominate near the equator:"

This quotation is frum a letter of mine published in NATURE of 16 th Feb.

In the same number of NATURE there is a letter from $\mathrm{Mr}$. Laughton, maintaining that rain may be caused by fires or explosions. This is contirmed by a fact mentioned by Humboldt in his Cosmos, that he once saw an eruption of the volcano of Cotapaxi in the Andes, during which the cone became red hot, and rain fell at an unusual time of the year.

In the same number is a most interesting account of the Winter Meteorological Observatory on Mount Washington in New England. Mount Washington must be much more isolated than mountains 10,000 feet high generally are; and I hope the opportunity may not be lost of making comparative barometric observations, extending over a considerable time, at the summit and the base. In NATURE of I gth January, you published a letter of mine on the importance of such a comparative series.

Old Forge, Dunmury, Co. Antrim, March is JOSEPH JOHN MURPHY

\section{Morell's Geometry}

IT was with no small surprise that I found myself accused by Mr. I. R. Morell, more than once in last week's NATURE, of having overlooked the fact "that all the proofs in the work ('Essentials of Geometry') are taken from French and German sources." Nothing to my mind could be more obvious than that throughout my review in NATURE for Feb. 23, I was criticising the performance of a compiler. In one instance, indeed-Mr. Morell has surely not already forgotten it-I took the trouble to show how Amiot's demonstration of the fundamental properties of parallels had been mutilated by him. must protest, too, against his claim to freedom from censure on the ground that he has merely copied passages from the works of our highest authorities; for it is about as reasonable as a claim to sanctity would be on the part of one who habitually, it is said, quotes Scripture for his own purposes.

Utterly ionoring the italics which I introduced, to save comment, into his definition of a plane angle, Mr. Morell quotes the Greek of Euclid and the English of Thomson, in justification, apparently, of the aptness of the introduction of the notion of revolution, which no one contested. He compels me, therefore, to draw his serious attention to the fact that neither of these geometers, nor anyother to my knowledge, ever confused mankind as he has done by speaking of the "inclination of two straight lines to a common point."

Mr. Morell has, lastly, the audacity to defend his pretended demonstration, on p. 44, of the theorem that two triangles are equal in every respect when the sides of one are respectively equal to the sides of the other, by stating, first, that it "is based on the previons pages ( 42 and 43 ), overlooked by the Reviewer "' and, secondly, that it " agrees almost word for word with Legendre." The first of these statements is absolutely incorrect; on pages 42 and 43 , there is not a word upon which the demonstration in question could be based. With respect to the second state- ment, I admit that Mr. Morell's demonstration substantially differs from Legendre's, as given by Blanchet, in Prop. xi. Bk. I, only by the omission of four words; and to show, by a striking example, what mischief scissors can do in Mr. Morell's hands, I will supply the four missing words, between brackets, in the following reproduction of his demonstration :-

"Let $\mathrm{ABC}, \mathrm{DEF}$, be two triangles, having $\mathrm{AB}=\mathrm{DE}$, $A C=D F, B C=E F$, then angle $A=D$; for if they werc unequal, sides $\mathrm{BC}$ and $\mathrm{EF}$ would be unequal [by the previous proposition]. Therefore $A=D . "$

The fact that Legfendre's most essential previous proposition is nowhere to be found in Morell's "Essentials of Geometry," sufficiently accounts for the omission of the four words above inserted. Mr. Morell, however, has yet to realise the fact that these omissions of his have converted a genuine demonstration into a mere assertion, or rather into a flagrant "violation of the most obvious of all logical rules."

Mr. Morell threatens, if space be given him, to show, on his "own authority," that he has "good arguments for what has been advanced." Before he does so let me remind him that logical demonstration, like the multiplication table, is more a subject for direct apprehension than for argument.

\section{THE ReVIEWER}

\section{A Meteorological Question}

WHILE glancing the other day over the article "Meteorology," in the Supplement to the 4th, 5th, and 6th Editions of the Enc' clopxdia Britannica, I was surprised to find under the marginal heading, "Hauhber's Experiment," the following:- "It is conceived that a current of air in sweeping over the surface of the earth, must cease to exert any vertical pressure. But this assumption can hardly be reconciled with any strict principles in science, for the particles of air will not for a moment cease to gravitate, nor will any horizontal motion of them produce the slightest de. rangement in a perpendicular direction." Is not this a great mistake? QUARE

\section{A SUGGESTED NEW DIVISTON OF THE EARTH INTO ZOOLOGICAL REGIONS}

$\mathrm{T} T$ seems now to be generally agreed among zoologists who are specially conversant with the fauna of India, that " the Indian Region" of Dr. Sclater and others can no longer be regarded as a genuine or natural zoological division of the globe, and that India properly so called (from the Himálya to the sea), is rather a border territory where different zoological regions meet and are variously interposed, at the same time blending, as a matter of course, to some extent.*

This is a subject which has long occupied my thoughts, and $I$ am gradually arriving at the opinion that the present dry land upon our planet may be most naturally divided into seven zoological regions, which again are divisible into sub-regions, and these into provinces and sub-provinces.

I. The Boreal Region, which is divisable into: I. Arctic Sub-region, within the confines of the Arctic Circle, but also inclusive of the whole of Greenland, and of Foxland (west of Davis Strait and north of Hudson Strait). 2. Neo-septentrional Sub-region-North America. 3. Ne meridional Sub-region-Central America with the Antilles. 4. Andisian Sub-region-the chain of the Andes with Chili, Patagonia, and the Fuegian and Falkland Archipelagos. 5. Palæo-septentrional Sub-region-Europe and Asia south of the Arctic Circle, and north of the Pyrenees, Alp; Taurus, Elburz (south of the Caspian Sea), Hindu Kosh, and Western Himálya, extending from the British Islands to Northern Japan? 6. Palæo-meridional Sub-region-the countries adjacent to the Mediterranean, as Africa north of the Atlas (with Madeira, the Canaries, and the Azores) Spain, Italy, Dalmatia and Illyria, Greece, the islands of the Mediterranean and the Levant, Turkey, Asia Minor,

*Vide Mr. W. T. Blanford in the "Proceedings of the Asiatic Society." for September 1867, p. I45 "The fauna of India at the present day is a remarkable mixture of African and Malay forms. The idea, so com monly expressed in European books, of India belonging to the same geological [qu. zoological?] province as the Malay Peninsula and Southern China is quite erroneous." Vide also the same " Proceedings" for January 1868 p. 18 , January 1869, p. 40 , and July 1870 , p. 238 . 